\title{
Using Variable Interval Reinforcement Schedules to Support Students in the Classroom: An Introduction With Illustrative Examples
}

\author{
David Hulac \\ University of Northern Colorado \\ Nicholas Benson \\ Baylor University \\ Matthew C. Nesmith \\ University of South Dakota \\ Sarah Wollersheim Shervey \\ University of South Dakota
}

\begin{abstract}
When behaviors are reinforced with a variable interval reinforcement schedule, reinforcement is available only after an unknown period of time. These types of reinforcement schedules are most useful for reinforcing slow and steady responding and for differentially reinforcing behaviors that are incompatible with some problematic behaviors. This review helps define variable interval reinforcement schedules, uses the example of a strategy to manage thumb-sucking behavior to illustrate the implementation of these schedules, and describes potential applications in school and clinical settings.
\end{abstract}

Keywords: classroom management, positive behavior supports, behavior analysis

\section{Introduction}

Fiona was a 5-year-old who had met normal developmental milestones but was displaying excessive thumb-sucking behavior that was causing social and dental problems. Previous attempts to reduce Fiona's thumb sucking (i.e., frequent cueing, encouraging her to practice an incompatible behavior, and trying to satiate her by setting aside thumb-sucking time) were having little effect on her behavior. Instead, it was thought that Fiona should be reinforced for other non-thumb-sucking behaviors. Working with Fiona, an interventionist developed a token economy system that involved providing a reward whenever a chime sounded. The chime was scheduled to sound on irregular intervals. If the chime sounded and Fiona's thumb was not in her mouth, she would get to make a mark on a piece of paper. One hundred marks would allow her to get a pack of sugar-free gum, a highly desirable and tangible reinforcer. During times when the token economy was in place, Fiona substantially reduced her thumb-sucking behavior.

While thumb-sucking, by itself, is not a common problem that many classroom teachers address, the above fictionalized example can provide teachers with a lens to better understand ways to manage negative behaviors and promote positive behaviors. After all, classroom teachers do experience a variety of behaviors that are detrimental to learning. While students with emotional behavior and developmental disorders may experience these behaviors more often, such behaviors can be 
experienced by any child in the classroom setting. In fact, there are infinitely many ways for students to display off-task behaviors. Teachers who attempt to create a plan for managing each type of misbehavior will likely find themselves in a reactive mode that results in frequent reprimands that can have a negative effect on the classroom environment.

In an effort to promote a positive learning environment, many teachers use a variety of interventions, including differential reinforcement of other behavior (Christensen \& Sanders, 1987) and token economy systems (Hackenberg, 2009), whereby student earn rewards for desirable behaviors. These types of interventions are relatively easy to implement if the target behavior is easily observable and countable. In a review of literature, Gresham, Van, and Cook (2006) found that increasing appropriate replacement behavior can lead to a decrease in negative behaviors. Some examples for students may be sitting in their seat or working independently without talking. However, other on-task behaviors are more difficult to count. For example, while not talking might be easy to observe, it is more difficult to determine if the student is working independently or merely engaging in silent off-task behavior. To better understand how to address these situations, this review will provide teachers and clinicians with an overview of schedules of reinforcement and will talk most specifically about the benefits of a type of reinforcement schedule known as a variable interval (VI) reinforcement schedule (Snell \& Cole, 1976).

\section{Schedules of Reinforcement}

\section{Continuous Reinforcement Schedules}

Imagine a situation where a student who refused to complete math problems received a piece of candy every time she completed one math problem accurately. It is likely that she would quickly make the connection between the math problems and the candy and would likely complete many math problems quickly to receive the candy. The development of math problem completion is known as behavioral acquisition - the student is acquiring the behavior rapidly because she is being rewarded for every behavioral occurrence. The technical term for this schedule is a continuous reinforcement schedule (Cooper, Heron, \& Heward, 2007). Of course, giving candy to a child for completing problems may be nutritionally problematic. It would also be difficult for a teacher to reinforce a high frequency behavior every time it occurs without working in a one-on-one situation. Moreover, once the teacher stops giving candy upon completion of the math problems, the student is likely to stop doing the math problems. This stopping is called extinction-a behavior stops once reinforcement stops (Baer, 1961). Behaviors reinforced by continuous reinforcement schedules are subject to high levels of extinction once the reinforcement is no longer available (Cooper et al., 2007; Hulac, Terrell, Vining, \& Bernstein, 2011). Thus, attempting to reinforce a behavior every time it occurs is likely to be impractical. In Fiona's case, a continuous reinforcement schedule would be inappropriate, as it would be inconsistent with the treatment goal of eliminating thumb-sucking behavior. If Fiona was placed on a continuous reinforcement schedule, the only way she could gain access to continuous reinforcement would be to alternate between sucking her thumb and not sucking her thumb. Although this would decrease the duration of her thumb-sucking behavior, it would have the unintended consequence of increasing the frequency of the number of times that she sticks her thumb in her mouth.

\section{Ratio Reinforcement Schedules}

Partial reinforcement is generally a more practical option for classroom settings than is continuous reinforcement. Rather than rewarding a behavior every time it occurs, it may be appropriate to reinforce a behavior some of the time. For example, we may reinforce the student with candy each 
time she completes seven problems. Researchers have found that subjects who are reinforced with these ratio reinforcement schedules acquire the behavior more slowly, but that these behaviors are somewhat resistant to extinction (e.g., Weiner, 1970). Further, they also result in behaviors occurring rapidly. However, teachers may find these reinforcement schedules impractical for a couple of reasons. The first is that a teacher must keep track of the number of times a behavior has occurred. Moreover, the rapid responding may not be appropriate for certain activities. For example, a student who responds rapidly to a math word problem may not take the necessary time to proofread or to read a problem carefully. Ratio reinforcement schedules may be appropriate for developing reading or math computational fluency with a skill where accurate and rapid responding is desired (Burns, VanDerHeyden, \& Boice, 2008).

\section{Interval Reinforcement Schedules}

Many teachers prefer to use interval reinforcement schedules whereby reinforcement only occurs after a period of time (intervals). There are two types of interval reinforcement schedules: fixed and variable. Perhaps the most famous example of a fixed interval scale is the term paper due date. The student is only reinforced or graded if the paper is in by a certain date. Unfortunately, most students don't begin working on term papers until the deadline is approaching. This also happens in the laboratory where the behavior of interest increases as the interval ends (Ferster \& Skinner, 1957). Besides encouraging procrastination, fixed interval reinforcement schedules also create a postreinforcement pause whereby the subject's behavior declines to low levels immediately after receiving a reinforcer (Lee \& Belfiore, 1997). Thus, once a reinforcer is no longer available, the student's behavior may decrease. In Fiona's case, if the interventionist sounded the chime to ring every $5 \mathrm{~min}$, it is likely that Fiona would have heard the chime, known that it was "safe" to put the thumb in her mouth, and would only have taken it out near the end of the 5-min interval.

Pop quizzes, however, are different. With pop quizzes, a student is unsure when the reinforcement for reading an assignment is going to occur. When done properly, pop quizzes encourage students to complete their reading on a more frequent basis. This reinforcement schedule is known as a VI schedule. Unlike variable ratio schedules that reinforce after a random number of incidents of behavior (such as a slot machine), a VI schedule is time based. The behaviors reinforced on this schedule are typically slow and steady. In fact, VI schedules of reinforcement are the best approaches for developing habitual behaviors that last for a long period of time (Domjan, 2000).

Technically, during a VI reinforcement schedule, a window of reinforcement availability opens. If a desired behavior is displayed within this window, then a reinforcer is provided. For the intervention with Fiona, the window of opportunity was small. At the moment of time when the chime sounded, the interventionist looked to see whether or not Fiona was sucking her thumb. Such a VI schedule may be appropriate for many behaviors teachers and other educators are looking to reinforce. This is especially true for behaviors that need to take place for a long period of time.

\section{Applications}

In school and clinical settings, there are many possible applications for VI reinforcement schedules to support student behavior. For individuals who are displaying out of seat behaviors, a token economy system could be created whereby the students receive tokens if they are in their seats whenever a bell that rings at a random interval sounds (e.g. Grandy \& Peck, 1997). Students may be taught self-management strategies they can use to rate their levels of various behaviors for the purpose of increasing self-awareness and communicating information regarding their behavioral progress to teachers. Some examples of student behaviors that teachers may be interested in include 
sitting up straight and tracking the teacher with their eyes. A chime that sounds on a VI schedule could be used to encourage students to rate their own performance on such tasks (Briesch, Hemphill, \& Daniels, 2013). In a classroom situation when a teacher is attempting to use a group contingency to reduce peer mediated behaviors (e.g. Hulac \& Benson, 2010), the teacher may give a command on a VI schedule to remind students about the desired ignoring behaviors. When working with two fourth graders who were frequently not working on their assignments, a teacher instituted an intervention whereby students received social attention if they were "on-task" when a timer went off on a cuing tape (Martens, Lochner, \& Kelly, 1992). Additionally, a teacher may consider VI reinforcement for any of the following common behavioral expectations:

- $\quad$ Remaining in a seat

- Talking in a quiet voice that is below a certain decibel level

- Keeping hands to self in the hallway and during work time

- $\quad$ Sitting with good posture in music class

- $\quad$ Keeping all unnecessary items off of desk

- Maintaining walking behavior in the hallway

- $\quad$ Putting papers in appropriate folders

- Maintaining appropriate organization of materials

- Following teacher directions

Even teachers who specialize in music instruction may find relevant VI applications. In the voice studio, which is a one-on-one teacher-student interaction, a major pedagogical goal is proper shape and structure of the oral cavity, jaw, and muscles of the face and mouth, over the course of full song, for the achievement of optimal tone quality and timbre specific to the style of the song. A chime set on a VI schedule would provide the reinforcement for the student to be consistent in maintaining optimal structure while singing. It also would facilitate setting the desired behavior into the student's muscle memory more quickly and effectively. In a group setting, such as a musical theatre production, the director may set a chime on a VI schedule during the course of a lengthy ensemble scene. The focus of the VI reinforcement would be to motivate the actors to always be play a strong, specific action that is germane to the scene and their character.

It may even be appropriate for teachers to use a VI schedule to monitor their own behavior. For example, teachers who want to increase the amount of specific praise they use to reinforce positive behaviors could utilize a timer set at random intervals to facilitate the delivery of praise on a random but more frequent basis.

\section{Creating Variable Interval Reinforcement Schedules}

It is helpful to obtain a timer that chimes on random intervals when implementing VI reinforcement schedules. An option that is available on the Internet is the mindfulness bell from www.mindfulnessdc.org/bell/. Some free smartphone apps include Random Timer, Lotus Bell, and a Hot Potato Party Game that all chime at random intervals. Second, create an expectation for what the student or students should be doing when the chime goes off. Create a reinforcement plan for what will happen if the students are meeting the expectation. The teacher can choose to make a mark on the board, drop a marble in a jar, or have the student make a mark on a sheet of paper. For individuals with intellectual disabilities, it may be necessary to provide a concrete reinforce such as food, the chance to play a short game, or attention. When the student(s) have earned a predetermined number of marks, provide a reward. 


\section{Additional Considerations}

Any behavior management plan must have clear, positively stated behavior that communicates what a child should do. If a child's proficiency with a task falls within the frustration level, meaning they do not know how to perform the task without explicit instruction, then reinforcement procedures such as VI reinforcement are not necessarily appropriate. When working at the frustration level, students benefit from direct, step-by-step instruction followed by immediate feedback and opportunities to practice. However, once a student has learned the basics, but is in need of fluency practice, VI schedules are appropriate.

Like all reinforcement systems, if a behavior is reinforced too frequently the subject may become satiated with the reinforcer and the reinforcer would lose its effectiveness (Lee \& Belfiore, 1997). Randomization of the reward may help limit this satiation (Parry-Crews et al., 2011). Likewise, if a reinforcement schedule is too thin, a subject may find other undesirable and disruptive behaviors more reinforcing. In other words, the reinforcer must be something that the child values (Pace, Ivancic, Edwards, Iwata, \& Page, 1985). Dunlap and Kern (1996) discussed the importance of involving student choice in the development of a reinforcement plan, as students are not only motivated by the reinforcer itself but also the control that they gain from being part of the process. Other strategies for determining preferable reinforcers may occur both through indirect observations or direct data collection such as student rating of preferred reinforcers (Hagopian, Long, \& Rush, 2004).

In addition to identifying desirable reinforcers, the rate of reinforcement may need to be fairly high when the developing behavior has just been taught but is not yet a regular part of a student's behavioral repertoire. When starting any token economy, a child must be successful early. Simply waiting for the child to do the behavior before rewarding it may not work. For Fiona's example, waiting until the thumb was out of her mouth and then "rigging" the chime to go off would allow her to get a point immediately. This creates behavioral momentum whereby the behavior has less resistance once it starts (Belfiore, Lee, Scheeler, \& Klein, 2002).

\section{Concluding Thoughts}

Teachers frequently have expectations for appropriate classroom behavior. One important way for them to support and increase such behaviors is to reinforce continuous positive behaviors. Whether these behaviors are replacements for problematic behaviors or behaviors that are determined to be a relevant part of the curriculum, it can often be difficult to identify effective but time-efficient methods to provide that reinforcement. Continuous behaviors can be rewarded quickly and easily by using a behavioral chime to remind teachers or interventionists to provide reinforcement to a child demonstrating a desirable behavior. As mentioned earlier, such interventions will be most useful if the child has the opportunity to be successful immediately. Given their efficiency as well as the likelihood that they will yield desired changes in behavior, VI reinforcement schedules are a useful component of an educational practitioner's intervention repertoire. 


\section{References}

Baer, D. M. (1961). Effect of withdrawal of positive reinforcement on an extinguishing response in young children. Child Development, 32, 67-74.

Belfiore, P. J., Lee, D. L., Scheeler, C., \& Klein, D. (2002). Implications of behavioral momentum and academic achievement for students with behavior disorders: Theory, application, and practice. Psychology in the Schools, 39, 171-179.

Burns, M. K., VanDerHeyden, A. M., \& Boice, C. H. (2008). Best practices in delivery of intensive academic interventions. In A. Thomas \& J. Grimes (Eds.), Best practices in school psychology (5th ed., pp. 1151-1162). Bethesda, MD: National Association of School Psychologists.

Briesch, A. M., Hemphill, E., \& Daniels, B. (2013). Check your SLANT: Adapting self-management for use as a class-wide intervention. School Psychology Forum, 7, 29-39.

Christensen, A. P., \& Sanders, M. R. (1987). Habit reversal and differential reinforcement of other behaviour in the treatment of thumb-sucking: An analysis of generalization and side-effects. Child Psychology \& Psychiatry \& Allied Disciplines, 28, 281-295. doi:10.1111/j.14697610.1987.tb00211.x

Cooper, J. O., Heron, T. E., \& Heward, W. L. (2007). Applied behavior analysis (2nd ed.). Upper Saddle River, NJ: Prentice Hall.

Domjan, M. (2000). The essentials of conditioning and learning, 2nd edition. Belmont, CA: Wadsworth.

Dunlap, G., \& Kern, L. (1996). Modifying instructional activities to promote desirable behavior: A conceptual and practical framework. School Psychology Quarterly, 11, 297-312. doi:10/1037/h0088936.

Ferster, C. B., \& Skinner, B. F. (1957). Schedules of reinforcement. New York, NY: AppletonCentury-Crofts.

Grandy, S. E., \& Peck, S. M. (1997). The use of functional assessment and self-management with a first grader. Child \& Family Behavior Therapy, 19, 29-43. doi:10.1300/J019v19n02_03

Gresham, F. M., Van, M. B., \& Cook, C. R. (2006). Social skills training for teaching replacement behaviors: remediating acquisition deficits in at-risk students. Behavioral Disorders, 31, 363-377.

Hackenberg, T. D. (2009). Token reinforcement: A review and analysis. Journal of the Experimental Analysis of Behavior, 91, 257-286.

Hagopian, L. P., Long, E. S., \& Rush, K. S. (2004). Preference assessment procedures for individuals with developmental disabilities. Behavior Modification, 28, 668-677. doi:10.1177/0145445503259836.

Hulac, D. M., \& Benson, N. (2010). The use of group contingencies for preventing and managing disruptive behaviors. Intervention in School and Clinic, 45, 257-262.

Hulac, D. M., Terrell, J., Vining, O., \& Bernstein, J. (2011). Behavioral interventions in schools. New York, NY: Routledge.

Lee, D. L., \& Belfiore, P. J. (1997). Enhancing classroom performance: A review of reinforcement schedules. Journal of Behavioral Education, 7, 205-217.

Libb, J., Sachs, C., \& Boyd, W. (1973). Reinforcement strategies for token economies in a special classroom setting. Psychological Reports, 32, 831-834. doi:10.2466/pr0.1973.32.3.83 
Martens, B. K., Lochner, D. G., \& Kelly, S. Q. (1992). The effects of variable-interval reinforcement on academic engagement: A demonstration of matching theory. Journal of Applied Behavior Analysis, 25, 143-151.

Pace, G. M., Ivancic, M. T., Edwards, G. L., Iwata, B. A., \& Page, T. J. (1985). Assessment of stimulus preference and reinforcer value with profoundly retarded individuals. Journal of Applied Behavior Analysis, 18, 249-255. doi:10.1901/jaba.1985.18-249.

Parry-Cruwys, D. E., Neal, C. M., Ahearn, W. H., Wheeler, E. E., Premchander, R., Loeb, M. B., \& Dube, W. V. (2011). Resistance to disruption in a classroom setting. Journal of Applied Behavior Analysis, 44, 363-367. doi:10.1901/jaba.2011.44-363

Snell, R., \& Cole, M. (1976). The use of a VI schedule of token reinforcement to effect all-day control of thumbsucking in the classroom. SALT: School Applications of Learning Theory, 9, 14-21.

Weiner, H. (1970). Instructional control of human operant responding during extinction following fixed-ratio conditioning. Journal of the Experimental Analysis of Behavior, 13, 391-394. doi:10.1901/jeab.1970.13-391.

The Journal of Educational Research and Practice provides a forum for studies and dialogue that allows readers to better develop social change in the field of education and learning. Journal content may focus on educational issues of all ages and in all settings. It also presents peer-reviewed commentaries, book reviews, interviews of prominent individuals, and additional content. The objectives: We publish research and related content that examines current relevant educational issues and processes aimed at presenting readers with knowledge and showing how that knowledge can be used to impact social change in educational or learning environments. Additional content provides an opportunity for scholarly and professional dialogue regarding that content's usefulness in expanding the body of scholarly knowledge and increasing readers' effectiveness as educators. The journal also focuses on facilitating the activities of both researcher-practitioners and practitioner-researchers, providing optimal opportunities for interdisciplinary and collaborative thought through blogging and other communications.

Walden University Publishing: http://www.publishing.waldenu.edu 